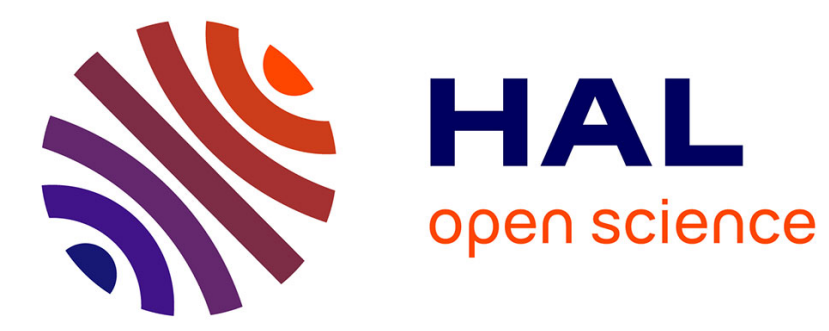

\title{
On the structure of $\mathrm{Ge}-\mathrm{As}-\mathrm{Te}-\mathrm{Cu}$ glasses
}

Pal Jóvári, Pierre Lucas, Zhiyong Yang, Bruno Bureau, Ivan Kaban, Brigitte

Beuneu, Claudia Pantalei, Jozef Bednarčik

\section{To cite this version:}

Pal Jóvári, Pierre Lucas, Zhiyong Yang, Bruno Bureau, Ivan Kaban, et al.. On the structure of $\mathrm{Ge}-\mathrm{As}-\mathrm{Te}-\mathrm{Cu}$ glasses. Journal of Non-Crystalline Solids, 2016, 433, pp.1-5. 10.1016/j.jnoncrysol.2015.11.003 . hal-01236430

HAL Id: hal-01236430

https://hal-univ-rennes1.archives-ouvertes.fr/hal-01236430

Submitted on 9 Dec 2015

HAL is a multi-disciplinary open access archive for the deposit and dissemination of scientific research documents, whether they are published or not. The documents may come from teaching and research institutions in France or abroad, or from public or private research centers.
L'archive ouverte pluridisciplinaire HAL, est destinée au dépôt et à la diffusion de documents scientifiques de niveau recherche, publiés ou non, émanant des établissements d'enseignement et de recherche français ou étrangers, des laboratoires publics ou privés. 


\section{On the structure of $\mathrm{Ge}-\mathrm{As}-\mathrm{Te}-\mathrm{Cu}$ glasses}

Pál Jóvári ${ }^{1}$, Pierre Lucas ${ }^{2}$, Zhiyong Yang ${ }^{2, a}$, Bruno Bureau ${ }^{3}$, Ivan Kaban ${ }^{4}$, Brigitte Beuneu ${ }^{5}$, Claudia Pantalei ${ }^{5}$, Jozef Bednarčik ${ }^{6}$

\footnotetext{
${ }^{1}$ Wigner Research Centre for Physics, Institute of Solid State Physics, H-1525 Budapest, POB 49, Hungary

${ }^{2}$ Department of Materials Science and Engineering, University of Arizona, Tucson, AZ, USA 85721

${ }^{3}$ Equipe Verres et Ceramiques, Laboratoire Sciences Chimiques de Rennes UMR-CNRS 6226, France

${ }^{4}$ IFW Dresden, Institute for Complex Materials, P.O. Box 270116, 01171 Dresden, Germany

${ }^{5}$ Laboratoire Léon Brillouin, CEA-Saclay 91191 Gif sur Yvette Cedex France

${ }^{6}$ Deutsches Elektronen-Synchrotron DESY, Photon Science, Notkestrasse 85, 22603 Hamburg,
}

Germany

${ }^{a}$ Now at Jiangsu Key Laboratory of Advanced Laser Materials and Devices, School of Physics and Electronic Engineering, Jiangsu Normal University, Xuzhou, Jiangsu 221116, China

\section{Abstract}

Short range order in glassy $0.9\left(\mathrm{Ge}_{0.1} \mathrm{As}_{0.15} \mathrm{Te}_{0.75}\right)-0.1 \mathrm{Cu}(\mathrm{GATC} 1)$ and $0.9\left(\mathrm{Ge}_{0.05} \mathrm{As}_{0.55} \mathrm{Te}_{0.4}\right)-$ 0.1Cu (GATC2) was studied by neutron- and X-ray diffraction as well as EXAFS (extended $\mathrm{X}$-ray absorption fine structure) measurements at the K-edges of all components. The reverse Monte Carlo simulation technique was used to create models consistent with all experimental datasets. It was found that $\mathrm{Cu}$ binds predominantly to Te in GATC1 while $\mathrm{Cu}-\mathrm{As}$ and $\mathrm{Cu}-\mathrm{Cu}$ bonding is also significant in GATC2. Ge and As atoms have 4 and $3 \mathrm{Ge} / \mathrm{As} / \mathrm{Te}$ neighbors in both compositions. In GATC1 the formation of 'extra' Te-Te bonds can be observed, similarly to $\mathrm{GeTe}_{4}-\mathrm{AgI}$ glasses.

\section{Introduction}

As-Te alloys can be vitrified over a broad composition range ( 20-60 at.\% As). A detailed study of As-Te glasses by diffraction techniques and EXAFS revealed that they could be considered as random covalent networks, without any type of preferred bonding [1-3]. The Ge-Te system behaves in a completely different way: liquid Ge-Te alloys can be vitrified only in the vicinity of the eutectic composition (15-20 at. \% Ge). A reverse Monte Carlo simulation study using EXAFS and diffraction datasets showed that Ge-Ge bonding is not significant in these glasses [4]. Later this finding was confirmed by EXAFS and X-ray photoelectron 
spectroscopy [5]. Given the sensitivity of the experimental techniques applied it means that the Ge-Ge coordination number is not higher than $\sim 0.3$, thus amorphous Ge-Te alloys around the eutectic composition should be regarded as chemically ordered.

Ge-As-Te (GAT) alloys can be vitrified between $\sim 80 \%$ and $\sim 35 \%$ Te content. The different behaviour of As and Ge in binary tellurides is also inherited by the ternary glasses. There is a pronounced ordering around Ge atoms, which prefer Te to As and Ge while As-As bonding is significant even in Te-rich compositions (e.g. $\mathrm{Ge}_{10} \mathrm{As}_{15} \mathrm{Te}_{75}$ ) [6].

Glass formation in the Ge-As-Te-Cu (GATC) system has been reported recently [7]. GATC glasses have excellent transmission in the IR range and possess high conductivity. This favorable combination of properties makes them suitable for detecting charged biomolecules by electrodepositing them and measuring their IR spectra.

The aim of the present study is the determination of the short range order in GATC. Comparison of the structure of GAT and GATC glasses reveals how $\mathrm{Cu}$ atoms modify the $\mathrm{Ge}$ As-Te covalent network. This question is especially interesting because glassy tellurides can host modifiers by entirely different mechanisms. For example, in $0.75 \mathrm{GeTe}_{4}-0.25 \mathrm{AgI}$ the total coordination number of $\mathrm{Te}$ is close to 3 and the sum of $\mathrm{Te}-\mathrm{Ge}$ and $\mathrm{Te}-\mathrm{Te}$ coordination numbers is 2.76 [8]. Therefore, in this case $\mathrm{Ag}$ and I induce a strong rearrangement of the $\mathrm{Ge}-$ Te covalent network. On the other hand, in Ge-Ga-Te [4] and Te-rich Ge-Cu-Te [9] glasses the sum of Te-Te and Te-Ge coordination numbers remains close to 2 but the total coordination number of Te is significantly higher than 2 , showing that modifying atoms form additional bonds with Te but do not rearrange the host network.

Chemical short range order in an alloy can be characterized by the partial pair correlation functions. The number of these functions in case of an $n$-component system is $n(n+1) / 2$. As four-component glasses have ten partial pair correlation functions the detailed description of the short range order of Ge-As-Te-Cu glasses is a rather challenging goal. Close distances (e.g. Ge-Te, As-Te, $\mathrm{Cu}-\mathrm{Te}$ ) can be separated reliably only by combining various experimental techniques. For this reason we have carried out neutron and X-ray diffraction experiments as well as EXAFS measurements at the $\mathrm{K}$ absorption edges of all components. Large scale structural models have been created by fitting simultaneously the 6 experimental datasets in the framework of the reverse Monte Carlo simulation technique [10, 11]. Besides fitting experimental data, this method is also capable of incorporating existing physical and chemical information (e.g. density, preferred coordination numbers, chemical ordering) in the models created. The use of various constraints also gives the possibility of 
estimating the uncertainty of coordination numbers or assessing the validity of various structural models, in general.

\section{Sample preparation}

Both glass samples were prepared using high purity elements $(99.999 \% \mathrm{Ge}$ and $\mathrm{Cu}$, 99.99999\% As, and 99.9999\% Te) introduced in a silica ampoule which was flame sealed under high vacuum. The melt was homogenized for $8 \mathrm{~h}$ in a rocking furnace at $850^{\circ} \mathrm{C}$. After homogenization, the temperature of the furnace was lowered to $600^{\circ} \mathrm{C}$ to reduce the vapour pressure and after an isothermal heating for 1 hour the ampoule was quenched in water. The ampoule containing the glass was then immediately annealed at $20^{\circ} \mathrm{C}$ below the glass transition temperature $T_{g}$ for 3 hour. The resulting glass rod was recovered by breaking the silica ampoule.

\section{Experimental}

The neutron diffraction experiment was carried out at the 7C2 liquid and amorphous diffractometer of the Laboratoire Léon Brillouin (Saclay, France). Powdered samples were filled into thin walled vanadium sample holders (diameter: $6 \mathrm{~mm}$, wall thickness: $0.1 \mathrm{~mm}$ ). $0.9\left(\mathrm{Ge}_{0.1} \mathrm{As}_{0.15} \mathrm{Te}_{0.75}\right)-0.1 \mathrm{Cu}$ was measured with the old 'banana' detector filled with $\mathrm{BF}_{3}$. The new $3 \mathrm{He}$-filled detector system was used to measure $0.9\left(\mathrm{Ge}_{0.05} \mathrm{As}_{0.55} \mathrm{Te}_{0.4}\right)-0.1 \mathrm{Cu}$. Raw data were corrected for background scattering and detector efficiency. The offset of the detector position and the wavelength of the incident neutron beam $(0.72 \AA)$ were determined by measuring a Ni standard.

The X-ray diffraction and EXAFS experiments are described in ref. [6].

\section{Reverse Monte Carlo simulation}

The reverse Monte Carlo simulation technique was used to generate particle configurations fitting all experimental datasets and using available physical information. Simulation boxes contained 20000 atoms.

Density measurements of $\mathrm{Ge}_{15} \mathrm{Te}_{85}-\mathrm{Cu}$ glasses [12] revealed that the partial molar volume of the $\mathrm{Ge}_{15} \mathrm{Te}_{85}$ host matrix (i.e. the volume in which 0.15 mole Ge and 0.85 mole $\mathrm{Te}$ can be found) does not depend significantly on the $\mathrm{Cu}$ content (up to 10 atomic \%). Molar volume of GATC1 was therefore estimated by multiplying the molar volume of $\mathrm{Ge}_{10} \mathrm{As}_{15} \mathrm{Te}_{75}$ 
[6] by 0.9. Similar measurements showed that the partial molar volume of $\mathrm{As}_{50} \mathrm{Te}_{50}$ is $\sim 1.8 \%$ greater in $\mathrm{As}_{50} \mathrm{Te}_{50}-10 \% \mathrm{Cu}$ than in the undoped binary glass [12]. It is reasonable to assume that the 'breathing' of the host matrix increases with decreasing Te content due to the decreasing average distance of the atoms. Thus the molar volume of GATC2 was taken to be only $6 \%$ smaller than that of $\mathrm{Ge}_{5} \mathrm{As}_{55} \mathrm{Te}_{40}$ (see Table 1). Test runs revealed that small $( \pm 3 \%)$ changes of the density have no significant effect on short range order parameters.

Minimum interatomic distances are listed in Table 2. Backscattering factors needed to calculate the model EXAFS curves from partial pair correlation functions [13] were obtained by the feff8.4 programme [14]. Raw $\chi(\mathrm{k})$ data were filtered in two steps: first $\mathrm{k}^{3} \chi(\mathrm{k})$ was forward Fourier-transformed into r-space using a Kaiser-Bessel window $(\alpha=1.5)$. The k-range of transformation was around $1.8 \AA^{-1}-14 \AA^{-1}$ for the As and Te K edges and around $1.8 \AA^{-1}$ $12.5 \AA^{-1}$ for the $\mathrm{Ge}$ and $\mathrm{Cu}$ edges. The resulting $\mathrm{r}$-space data were backtransformed using a rectangular window (usually over the r-space range $1.2 \AA-3.2 \AA$ ).

\section{Results and discussion}

\section{1. $0.9\left(\mathrm{Ge}_{0.1} \mathrm{As}_{0.15} \mathrm{Te}_{0.75}\right)-0.1 \mathrm{Cu}$}

First the environment of Ge atoms was investigated. It was found that the elimination of $\mathrm{Ge}$ $\mathrm{Ge}, \mathrm{Ge}-\mathrm{As}$ and $\mathrm{Ge}-\mathrm{Cu}$ bonds does not influence the quality of fits. Therefore Ge atoms were allowed to have only Te neighbors and the Ge-Te coordination number was constrained to be 4. The Ge-Te bond length $(2.60 \pm 0.02 \AA)$ is in a good agreement with literature values $[4,6$ $15,16]$.

Arsenic binds mostly to Te but As-As bonding also improved fit qualities. The total coordination number of As was constrained to be 3. $\mathrm{N}_{\text {AsAs }}$, the As-As coordination number is $0.33 \pm 0.2$ which is very close to the corresponding value (0.39) of $\mathrm{Ge}_{10} \mathrm{As}_{15} \mathrm{Te}_{75}$ glass [6].

$\mathrm{Cu}$ has on the average $3.37 \pm 0.3$ Te neighbors. The mean $\mathrm{Cu}$-Te distance is $2.56 \pm 0.02$ $\AA$, which agrees with the value found in amorphous $\mathrm{GeCu}_{2} \mathrm{Te}_{3}$ [17]. It was established that the fit of the $\mathrm{Cu}$ K-edge EXAFS data was improved upon allowing $\mathrm{Cu}-\mathrm{Cu}$ bonding. However, the position of the first peak of $g_{\mathrm{CuCu}}(r)$, the $\mathrm{Cu}-\mathrm{Cu}$ partial pair correlation function, was strongly sensitive to the parameters of the fit (e.g. fitting range, weight of the Cu EXAFS dataset). Therefore it has been concluded that $\mathrm{Cu}-\mathrm{Cu}$ bonding in the model is an artefact and the real $\mathrm{Cu}-\mathrm{Cu}$ coordination number is most likely below the sensitivity of our approach.

The total coordination number of $\mathrm{Te}$ is $2.74 \pm 0.2$. The average number of $\mathrm{Cu}$ atoms around Te is $0.50 \pm 0.1$ while the number of 'covalent' neighbours (Ge, As, Te) is 2.24 \pm 0.2 . 
Comparison with $\mathrm{Ge}_{10} \mathrm{As}_{15} \mathrm{Te}_{75}$ reveals that the first minimum of $g_{\mathrm{TeTe}}(r)$ becomes less well defined upon adding $\mathrm{Cu}$ (Fig. 3). The shoulder at $2.9 \AA$ suggests that 'extra' Te atoms appear in the first coordination sphere of Te and increase the average coordination number of Te by forming a third covalent bond, similarly to the $\mathrm{GeTe}_{4}$ - $\mathrm{AgI}$ system [8].

\section{2. $0.9\left(\mathrm{Ge}_{0.05} \mathrm{As}_{0.55} \mathrm{Te}_{0.4}\right)-0.1 \mathrm{Cu}$}

As this composition is strongly Te-poor Ge cannot be fourfold coordinated without significant Ge-As bonding (see Table 2). Nevertheless, Ge-Te bonds are clearly preferred to Ge-As ones. Neither Ge-Ge nor Ge-Cu bonding was found to improve fit quality therefore these pairs were forbidden by raising the corresponding minimum interatomic distances (Table 2). Besides Ge, arsenic is mostly surrounded by Te and As. However, test runs showed that $\mathrm{Cu}$ also binds to arsenic. The $\mathrm{Cu}$-As coordination number is $1.43 \pm 0.7$. Given the high percentage of As, this value still indicates that $\mathrm{Cu}-\mathrm{Te}$ bonds are strongly preferred to $\mathrm{Cu}$ - $\mathrm{As}$ ones. The $\mathrm{Cu}-\mathrm{Cu}$ coordination number is $1.83 \pm 1$. The individual uncertainties of $\mathrm{Cu}-\mathrm{X}$ coordination numbers are rather high but they largely cancel each other, similarly to the case of GATC1. Therefore the total coordination number of $\mathrm{Cu}$ is relatively well defined (4.45 \pm 0.4$)$. Though Te-Te bonding was allowed, the Te-Te coordination number is only 0.03 . This value is well below the sensitivity of our approach therefore Te-Te bonding is not significant in GATC2.

\subsection{Comparison with the structure of other amorphous chalcogenides}

The Ge-Te distance is $2.60 \pm 0.02 \AA$ both in GATC1 and GATC2. The same bond length was found in several Ge-Te based glasses $[4,6,15,16]$ showing that the strength of Ge-Te bonds is not strongly sensitive to the composition. This is definitely not true for the Te-Te distance that shows a great variation even in amorphous Ge-Te films, with a well-defined maximum around $\mathrm{Ge}_{20} \mathrm{Te}_{80}$ [18]. The Te-Te distance also seems to depend on how the modifier binds to the atoms of the host network: in case of covalent bonding (e.g. Se and I) the bond length becomes smaller (2.70-2.73 $\AA$ ) while Ga increases the mean Te-Te distance to 2.79-2.80 $\AA$ [4]. In GATC1 and in $\mathrm{Ge}_{10} \mathrm{As}_{15} \mathrm{Te}_{75}$ the Te-Te bond length is $2.78 \pm 0.02 \AA$ and $2.76 \pm 0.02 \AA$, respectively.

$\mathrm{Cu}$-Te distances also lie in a rather narrow range (2.56-2.58 $\AA$ ) in GATC1, GATC2, and $\mathrm{GeCu}_{2} \mathrm{Te}_{3}$ [17]. The electronegativity of $\mathrm{Cu}$ is 1.9 while that of Te is 2.1 . These are very close, hence the $\mathrm{Cu}$-Te bond is expected to be covalent. This is confirmed by the fact that the investigated Ge-As-Te-Cu glasses are amorphous semiconductors with a bandgap around 1 $\mathrm{eV}$ [7], which is much smaller than the typical values of ionic compounds. 
On the other hand, the scattering of $\mathrm{Cu}-\mathrm{Cu}$ bond lengths is rather large (2.55-2.81 $\AA$ ). We believe that this is only partly due to the somewhat higher uncertainty of $\mathrm{Cu}$-related structural parameters. The $\mathrm{Cu}-\mathrm{Cu}$ distance is strongly sensitive to the environment of $\mathrm{Cu}$ atoms. For example in $\mathrm{Cu}_{2} \mathrm{Te}$ it is as short as $2.446 \AA$ [19] while in crystalline $\mathrm{Cu}_{1.4} \mathrm{Te}$ (rickardite) nearest $\mathrm{Cu}-\mathrm{Cu}$ distances are $2.58 \AA$ and $2.81 \AA$ [20]. $\mathrm{Cu}-\mathrm{Cu}$ distances found in various amorphous and crystalline copper tellurides are listed in Table 5.

\section{Conclusions}

The structure of $0.9\left(\mathrm{Ge}_{10} \mathrm{As}_{15} \mathrm{Te}_{75}\right)-0.1 \mathrm{Cu}$ and $0.9\left(\mathrm{Ge}_{5} \mathrm{As}_{55} \mathrm{Te}_{40}\right)-0.1 \mathrm{Cu}$ chalcogenide glasses has been investigated by diffraction and EXAFS measurements. Experimental data (six datasets for each composition) have been fitted simultaneously by the reverse Monte Carlo simulation technique. Ge is fourfold coordinated in both compositions. In $\mathrm{Ge}_{5} \mathrm{As}_{55} \mathrm{Te}_{40}-10 \mathrm{Cu}$ the total coordination number of As is higher than 3 due to the formation of $\mathrm{Cu}-\mathrm{As}$ bonds. $\mathrm{Cu}-$ $\mathrm{Cu}$ bonding is significant in $\mathrm{Ge}_{5} \mathrm{As}_{55} \mathrm{Te}_{40}-10 \% \mathrm{Cu}$ thus the prevalence of $\mathrm{CuTe}_{4}$ structural units can be ruled out in this composition.

\section{Acknowledgments}

The research leading to these results has received funding from the European Community's Seventh Framework Programme (FP7/2007-2013) under grant agreement no. 312284. P.J. was supported by OTKA (Hungarian Basic Research Fund) Grant No. 083529. This research was supported by the Partner University Fund, and the CNRS International Associated Laboratory for Materials \& Optics (LIA-MATEO). 
References

[1] P. Jóvári, S.N. Yannopoulos, I. Kaban, A. Kalampounias, I. Lischynskyy, B. Beuneu, O. Kostadinova, E. Welter, A. Schöps, J. Chem. Phys. 129 (2008) 214502

[2] D. C. Kaseman, I. Hung, K. Lee, K. Kovnir, Z. Gan, B. Aitken, S. Sen, J. Phys. Chem. B 119 (2015) 2081

[3] A. Tverjanovich, K. Rodionov, E. Bychkov, J. Solid State Chem. 190 (2012) 271

[4] P. Jóvári, I. Kaban, B. Bureau, A. A. Wilhelm, P. Lucas, B. Beuneu, D. A. Zajac, J. Phys. Condens. Matter 22 (2010) 404207

[5] R. Golovchak, L. Calvez, B. Bureau, H. Jain, J. Chem. Phys. 139 (2013) 054508

[6] P Jóvári, P. Lucas, Z Yang, B Bureau, I Kaban, B Beuneu, J Bednarčik, J. Am. Ceram. Soc. 97 (2014) 1625

[7] Z. Yang, A.A.Wilhelm, P. Lucas, J. Am. Ceram. Soc. 93 (2010) 1941

[8] P Jóvári, S Cui, V Nazabal, I Kaban, B Beuneu, M Dussauze, C Boussard-Plédel, B Bureau, J. Am. Ceram. Soc. 98 (2015) 1034

[9] L. Rátkai, A.P. Gonçalves, G. Delaizir, C. Godart, I. Kaban, B. Beuneu, P. Jóvári, Cu and Te coordination environment in Cu-doped Ge-Te glasses, Solid State Communications 151 (2011) 1524

[10] R.L. McGreevy, L. Pusztai, Mol. Simul. 1 (1988) 359

[11] O. Gereben, P. Jóvári, L. Temleitner, L. Pusztai, J. Optoelectron. Adv. Mater. 9 (2007) 3021

[12] Z.U. Borisova, Glassy Semiconductors, Plenum, New York (1981)

[13] M. Winterer, J. Appl. Phys., 88 (2000) 5635

[14] A.L. Ankudinov, B. Ravel, J.J. Rehr, S.D. Conradson, Phys. Rev. B, 58 (1998) 7565

[15] P. Jóvári, I. Kaban, J. Steiner, B. Beuneu, A. Schöps, M.A. Webb, Phys. Rev. B 77 (2008) 035202

[16] P. Jóvári, I. Kaban, J. Steiner, B. Beuneu, A. Schöps, M.A. Webb, J. Phys.: Condens. Matter 19 (2007) 335212

[17] P. Jóvári, Y. Sutou, I. Kaban, Y. Saito, J. Koike, Scripta Mater. 68 (2013) 122

[18] P Jóvári, A Piarristeguy, R Escalier, I Kaban, J Bednarčik, A. Pradel, J. Phys.: Condens. Matter 25 (2013) 195401

[19] H. Nowotny, Z. Metallkd. 37 (1946) 40

[20] S.A. Forman, M.A. Peacock, Amer. Mineralogist 34 (1950) 441 
[21] L. Bindi, C. Carbone, D. Belmonte, R. Cabella, R. Bracco, Mineralogical Magazine 77 (2013) 475

[22] Y.C. Wang, F.J. DiSalvo, J. Solid State Chem. 156 (2001) 44

[23] K.O. Klepp, J. Less-Common Met. 128 (1987) 79 
Table 1. Estimated molar volumes (in $\mathrm{cm}^{3}$ ) of GATC1 and GATC2 used in the reverse Monte Carlo simulation. The values of the corresponding undoped glasses [6] are also given for comparison.

\begin{tabular}{|l|l|}
\hline $\mathrm{GATC} 1$ & 18.32 \\
\hline $\mathrm{Ge}_{10} \mathrm{As}_{15} \mathrm{Te}_{75}$ & 20.35 \\
\hline $\mathrm{GATC2}$ & 16.88 \\
\hline $\mathrm{Ge}_{5} \mathrm{As}_{55} \mathrm{Te}_{40}$ & 17.96 \\
\hline
\end{tabular}

Table 2. Minimum interatomic distances (in $\AA$ ) used in the reverse Monte Carlo modelling of $0.9\left(\mathrm{Ge}_{0.10} \mathrm{As}_{0.15} \mathrm{Te}_{0.75}\right)-0.1 \mathrm{Cu}$ and $0.9\left(\mathrm{Ge}_{0.05} \mathrm{As}_{0.55} \mathrm{Te}_{0.4}\right)-0.1 \mathrm{Cu}$ (values in parentheses)

\begin{tabular}{|c|c|c|c|c|c|c|c|c|c|}
\hline Ge-Ge & Ge-As & Ge-Cu & Ge-Te & As-As & As-Cu & As-Te & $\mathrm{Cu}-\mathrm{Cu}$ & $\mathrm{Cu}-\mathrm{Te}$ & $\mathrm{Te}-\mathrm{Te}$ \\
\hline 3.6 & $3.6(2.35)$ & 3.1 & 2.35 & 2.35 & $3.1(2.65)$ & 2.35 & $3.1(2.45)$ & 2.35 & 2.5 \\
\hline
\end{tabular}

Table 3. Coordination numbers of $0.9\left(\mathrm{Ge}_{0.10} \mathrm{As}_{0.15} \mathrm{Te}_{0.75}\right)-0.1 \mathrm{Cu}$ and $0.9\left(\mathrm{Ge}_{0.05} \mathrm{As}_{0.55} \mathrm{Te}_{0.4}\right)$ $0.1 \mathrm{Cu}$ obtained by simultaneous fitting of diffraction and EXAFS datasets. Values in bold were obtained by coordination number constraints, therefore no uncertainty is given.

\begin{tabular}{|l|l|l|}
\hline & GATC1 & GATC2 \\
\hline & - & $1.80 \pm 0.6$ \\
\hline$N_{\text {GeAs }}$ & $\mathbf{4 . 0 0}$ & $2.20 \pm 0.6$ \\
\hline$N_{\text {GeTe }}$ & - & $0.16 \pm 0.05$ \\
\hline$N_{\text {AsGe }}$ & $0.37 \pm 0.2$ & $1.48 \pm 0.3$ \\
\hline$N_{\text {AsAs }}$ & - & $0.28 \pm 0.1$ \\
\hline$N_{\text {AsCu }}$ & $2.62 \pm 0.2$ & $1.36 \pm 0.3$ \\
\hline$N_{\text {Aste }}$ & - & $1.40 \pm 0.4$ \\
\hline$N_{\text {CuAs }}$ & - & $1.91 \pm 0.4$ \\
\hline$N_{\text {CuCu }}$ & $3.37 \pm 0.3$ & $1.23 \pm 0.4$ \\
\hline$N_{\text {CuTe }}$ & $\mathbf{0 . 5 3}$ & $0.28 \pm 0.08$ \\
\hline$N_{\text {TeGe }}$ & $0.52 \pm 0.04$ & $1.87 \pm 0.4$ \\
\hline$N_{\text {TeAs }}$ & $0.50 \pm 0.1$ & $0.35 \pm 0.1$ \\
\hline$N_{\text {TeCu }}$ & $1.19 \pm 0.2$ & 0.03 \\
\hline$N_{\text {TeTe }}$ & $\mathbf{4 . 0 0}$ & $\mathbf{4 . 0 0}$ \\
\hline$N_{\text {Ge }}$ & $\mathbf{2 . 9 9}$ & $3.28 \pm 0.1$ \\
\hline$N_{\text {As }}$ & $3.37 \pm 0.3$ & $4.54 \pm 0.3$ \\
\hline$N_{\mathrm{Cu}}$ & $2.74 \pm 0.2$ & $2.53 \pm 0.2$ \\
\hline$N_{\text {Te }}$ & & \\
\hline & & \\
\hline & & \\
\hline & & \\
\hline & & \\
\hline & & \\
\hline & & \\
\hline
\end{tabular}

Table 4. Nearest neighbour distances (in $\AA$ ) found in $0.9\left(\mathrm{Ge}_{0.10} \mathrm{As}_{0.15} \mathrm{Te}_{0.75}\right)-0.1 \mathrm{Cu}$ and $0.9\left(\mathrm{Ge}_{0.05} \mathrm{As}_{0.55} \mathrm{Te}_{0.4}\right)-0.1 \mathrm{Cu}$ and in some Ge-Te, Ge-As-Te and $\mathrm{Ge}-\mathrm{Cu}-\mathrm{Te}$ glasses

\begin{tabular}{|l|l|l|l|l|l|l|}
\hline & GATC1 & GATC2 & $\mathrm{Ge}_{20} \mathrm{Te}_{80}[18]$ & GAT1[6] & GAT2[6] & $\mathrm{GeCu}_{2} \mathrm{Te}_{3}[17]$ \\
\hline$r_{\mathrm{GeAs}}$ & - & $2.47 \pm 0.02$ & - & - & - & \\
\hline$r_{\mathrm{GeTe}}$ & $2.60 \pm 0.02$ & $2.60 \pm 0.02$ & $2.60 \pm 0.02$ & $2.60 \pm 0.02$ & $2.61 \pm 0.02$ & $2.61 \pm 0.02$ \\
\hline$r_{\mathrm{AsAs}}$ & $2.45 \pm 0.02$ & $2.45 \pm 0.02$ & - & $2.45 \pm 0.02$ & $2.43 \pm 0.02$ & \\
\hline
\end{tabular}




\begin{tabular}{|l|l|l|l|l|l|l|}
\hline$r_{\mathrm{AsCu}}$ & - & $2.76 \pm 0.02$ & - & - & - & \\
\hline$r_{\mathrm{AsTe}}$ & $2.60 \pm 0.02$ & $2.62 \pm 0.02$ & - & $2.60 \pm 0.02$ & $2.62 \pm 0.02$ & \\
\hline$r_{\mathrm{CuCu}}$ & - & $2.62 \pm 0.04$ & - & - & - & $2.55 \pm 0.02$ \\
\hline$r_{\mathrm{CuTe}}$ & $2.56 \pm 0.02$ & $2.57 \pm 0.02$ & - & - & - & $2.58 \pm 0.02$ \\
\hline$r_{\mathrm{TeTe}}$ & $2.78 \pm 0.02$ & - & $2.76 \pm 0.02$ & $2.76 \pm 0.02$ & $2.80 \pm 0.03$ & $2.75 \pm 0.02$ \\
\hline
\end{tabular}

Table 5. $\mathrm{Cu}-\mathrm{Cu}$ distances in some crystalline and amorphous copper tellurides (in $\AA$ )

\begin{tabular}{|l|c|}
\hline \multicolumn{1}{|c|}{ Composition } & $r_{\mathrm{CuCu}}$ \\
\hline $\mathrm{Cu}_{2} \mathrm{Te}[19]$ & 2.446 \\
\hline $\mathrm{Cu}_{1.4} \mathrm{Te}$ (rickardite) [20] & $2.58,2.81$ \\
\hline $\mathrm{Cu}_{1.79} \mathrm{Te}$ (weissite) [21] & $2.493-2.722$ \\
\hline $\mathrm{BaCu}_{2} \mathrm{Te}_{2}[22]$ & 2.847 \\
\hline $\mathrm{TlCu}_{3} \mathrm{Te}_{2}[23]$ & $2.474-2.890$ \\
\hline $\mathrm{GeCu}_{2} \mathrm{Te}_{3}[17]$ & $2.58 \pm 0.03$ \\
\hline $\mathrm{Ge}_{5} \mathrm{As}_{55} \mathrm{Te}_{40}-10 \% \mathrm{Cu}$ & $2.62 \pm 0.04$ \\
\hline
\end{tabular}




\section{Figure captions}

Figure 1. Comparison of measured diffraction and filtered experimental EXAFS datasets of $0.9\left(\mathrm{Ge}_{5} \mathrm{As}_{55} \mathrm{Te}_{40}\right)-0.1 \mathrm{Cu}$ (symbols) and the model curves (solid lines) obtained by reverse Monte Carlo simulation.

Figure 2. Partial pair correlation functions of $0.9\left(\mathrm{Ge}_{10} \mathrm{As}_{15} \mathrm{Te}_{75}\right)-0.1 \mathrm{Cu}$ (solid lines) and $0.9\left(\mathrm{Ge}_{5} \mathrm{As}_{55} \mathrm{Te}_{40}\right)-0.1 \mathrm{Cu}$ (symbols).

Figure 3. Comparison of the Te-Te partial pair correlation functions of $\mathrm{Ge}_{10} \mathrm{As}_{15} \mathrm{Te}_{75}$ [6] and $0.9\left(\mathrm{Ge}_{10} \mathrm{As}_{15} \mathrm{Te}_{75}\right)-0.1 \mathrm{Cu}$. 
Figure 1.
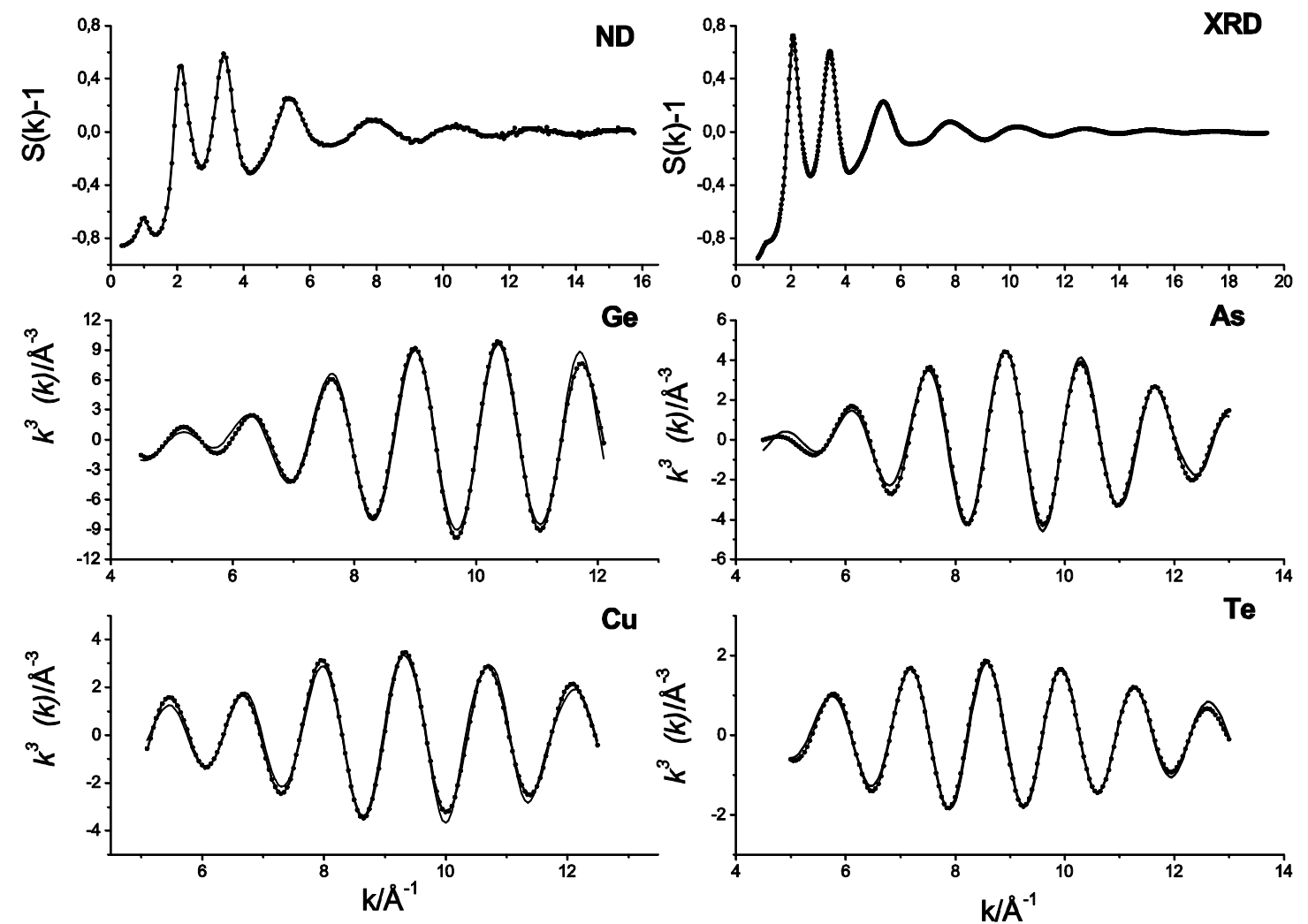
Figure 2.
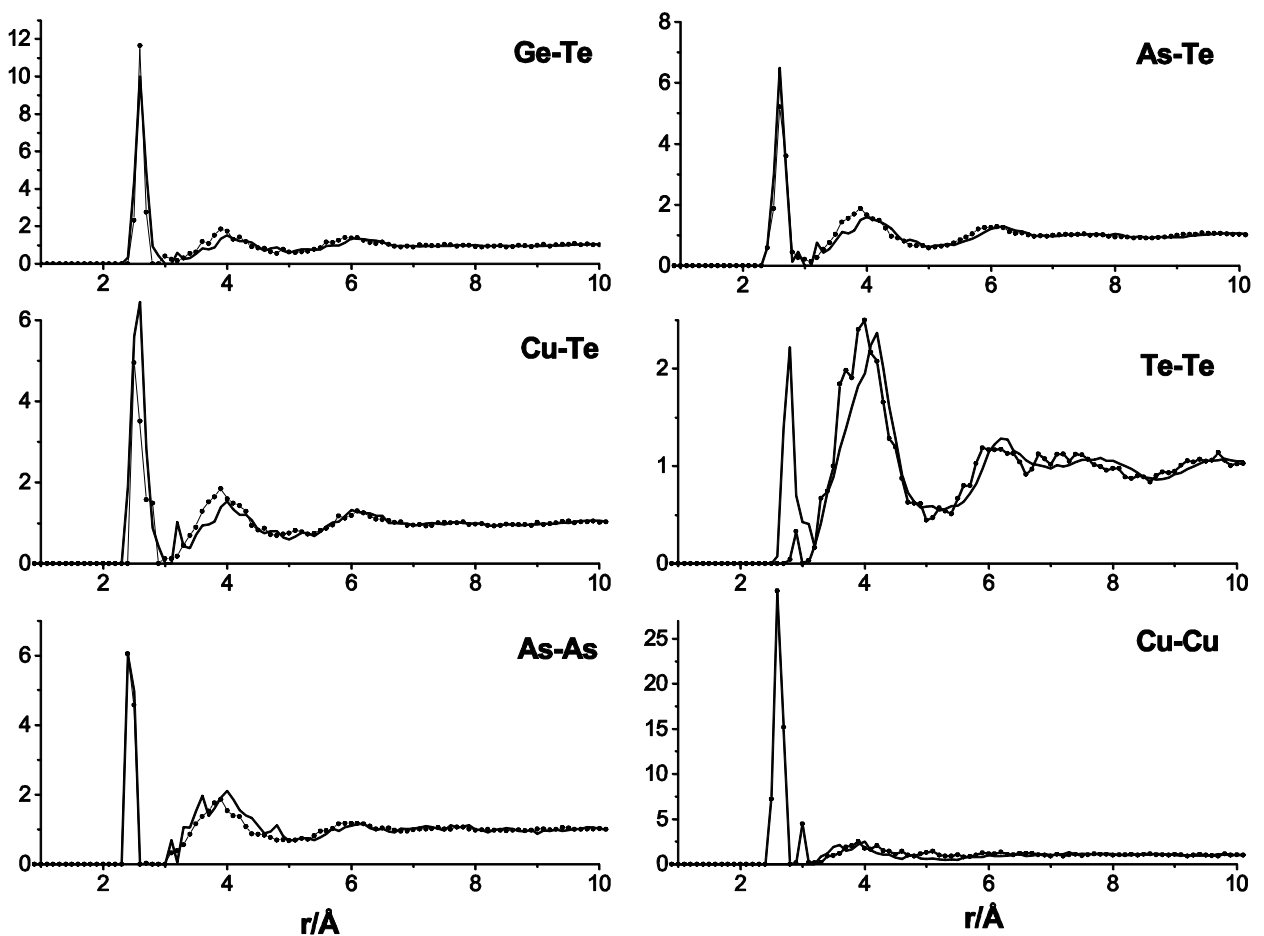
Figure 3.

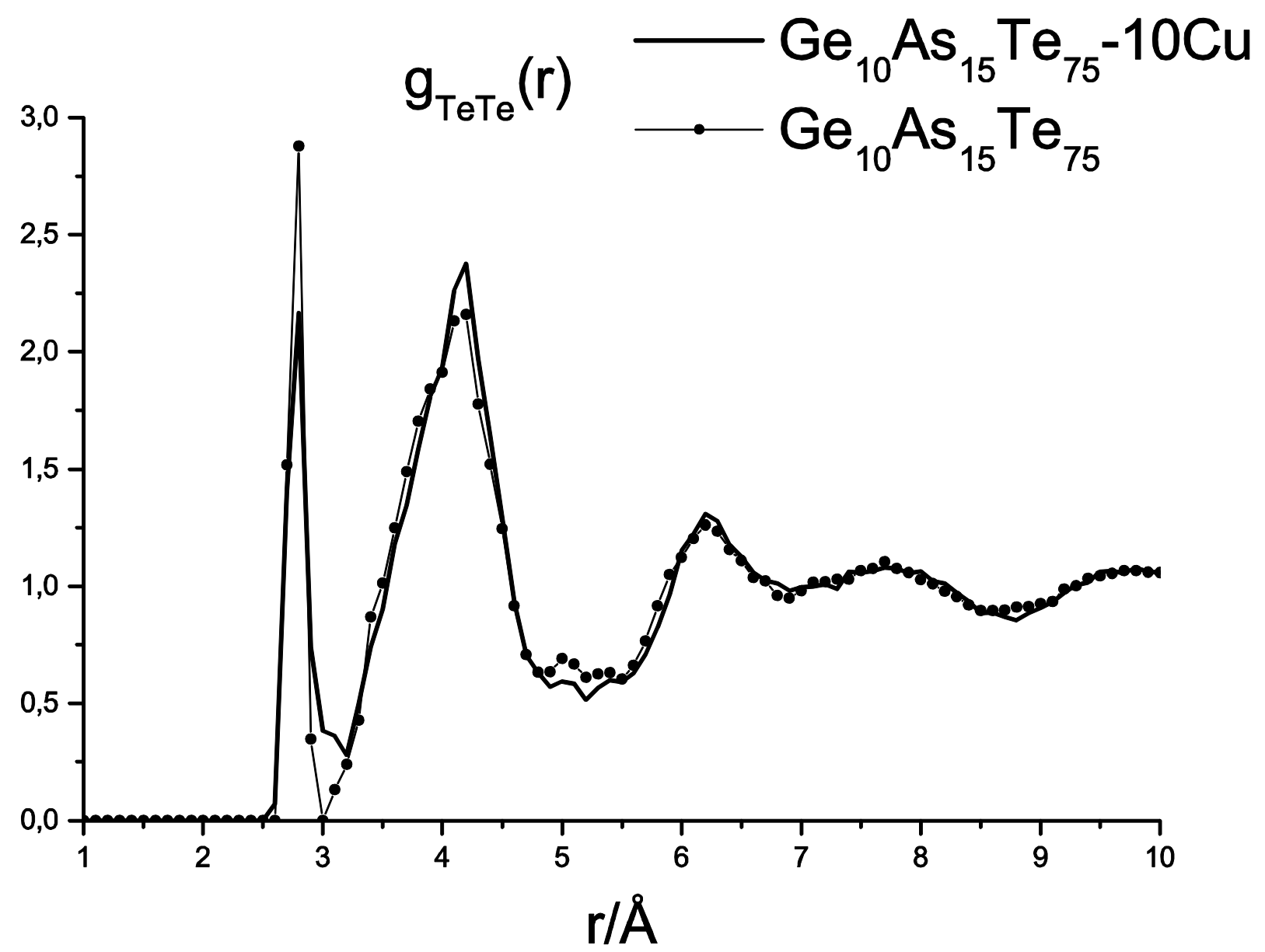

